\title{
Brittle fracture investigation from disc specimen weakened by $U$ - notch in mixed mode I + II
}

\author{
Mustafa Moussaoui ${ }^{a}$, Salah Amroune ${ }^{\text {b,c }}{ }^{*}$, Antar Tahiri ${ }^{a}$ and Brahim Khalil Hachi ${ }^{a}$
}

${ }^{a}$ Development Laboratory in Mechanics and Materials, University Ziane Achour, Djelfa, Algeria

${ }^{b}$ University of M'sila; B.P 166 ICHBELIA M'sila 28000, Algeria

${ }^{c}$ Laboratoire de Matériaux et Mécanique des Structures (LMMS), Université de M'sila. Algérie

\begin{tabular}{l}
\hline A R T I C L E I N F O \\
\hline Article history: \\
Received 28 September 2019 \\
Accepted 27 January 2020 \\
Available online \\
27 March 2020 \\
\hline Keywords: \\
Strain energy density \\
U-Notch \\
Brazilian disk \\
Mixed-mode I+II fracture \\
Stress intensity factor
\end{tabular}

\section{Introduction}

Many structures and components contain cracks or crack-like flaws or geometric discontinuities in which they can weaken the mechanical resistance. Many researches are developed and imposed instructions of manufacture to predict the behaviour of cracked structures and to guarantee their integrity. Brittle fracture is one of the frequent modes of failure in engineering materials. Since material defects such as cracks and notches have a significant role in the process of brittle fracture and there are not unavoidable, their investigations were based on fracture mechanics theory from various aspects. Linear elastic fracture mechanics (LEFM) remains applicable to the specimens in which the amount of plastic deformation around the crack tip is not considerable, so that elastic stresses and strains can be used to determine the mechanical behaviour of specimen. In reality, some situations result in a simultaneous presence of two modes of fracture: mode I (opening mode) and mode II (shear mode) which results in a higher degree of the difficulty of problem in brittle failure from notches than under only mode I. Several types of specimen shapes that were studied under various conditions, Richard's work (1989) was one of them, who used a number of specimens compact tension-shear, Brazilian disc, and etc. He investigated the effect of geometry on the mixed mode fracture toughness. The notched disc test has been widely used

* Corresponding author.

E-mail addresses: salah.amroune@univ-msila.dz (S. Amroune) and moussaoui must@yahoo.fr (M. Moussaoui) 
in different modes, in particular mixed mode, which consists of the combined action of two or more modes at the same time, they have proved theirs reliability in terms of the experimental results (Tamine et al. 1996; Torabi et al. 2015). The specimens considered are generally containing notches with different geometries in order to create phenomena similar to real cases; we can define the notch as an abrupt change in the geometry of a mechanical component. They may be necessary for design reasons, for example in a seat of a rolling bearing, in the seats of grooves in shafts, in holes for housing the pin, or rivets, or even in screws threads for a connection, they cause a change in the stress fields and deformations. Consequently this may influence the stress intensity factor and elastic density energy because the levels of stress concentration and also the stress gradients are generally different for variety of notches V, U and also VO-notches with end holes (key-hole) commonly seen in the industrial applications. The geometries most often counted are in the forms of $\mathrm{U}, \mathrm{V}$ and O-notches and their presence as we know induce important amplifications both in the stresses and deformations. Torabi et al. (2015) introduced a type of VO-shaped notch at the centre of Brazilian disc (VO-BD specimen) made with PMMA for different angles and various notch radii to predict mode II brittle fracture. Recently, new approaches for failure assessments have been appeared but their applications have been limited to the Vnotch. However, other types of notch geometries should also be studied to examine the ability to of such approaches. Kullmer and Richard (2006) have utilized a VO-notched for specimens under mixed mode I/II loading conditions. They have studied stress-based failure criterion for predicting the maximum static load that the compact-tension-shear-notch (CTSN) specimens made of PMMA. Torabi and Pirhadi (2015) have successfully analysed the fracture of notched graphite plates under mixed mode I/II using two stress-based criteria namely the MTS and the MS criteria. Some models are usually used by researchers in the study of mixed mode failure either theoretically using different failure criteria (Erdogan and Sih 1963; Sih 1974; Hussain et al. 1974) or experimentally using appropriate test methods, these tests are performed at the laboratories on model specimens. Due to the complexity and high cost of the experimental work on real models, these tests are performed at the laboratories on model specimens. However, these specimens must be carefully designed so as to behave under the same conditions as those of the actual technical components under these conditions of service. The researchers used various test samples for mixed mode I/II fracture experiments. The rectangular plate containing an inclined centre crack and subjected to a uniform far field tension (Williams and Ewing, 1972; Yukio et al. 1983), the centrally cracked Brazilian disk specimen (Aliha et al. 2006; Awaji and Sato 1978; Chang et al. 2002; Shetty et al. 1987, Akbardoost et al. 2014), the asymmetric three or four-point bend specimen (Choi et al. 2005; Suresh et al. 1990; Xeidakis et al. 1996; Fakhri et al. 2017; Razavi et al. 2018; Mousavi et al. 2020a,b); the angled edge crack specimen (Seed and Nowell, 1994), the compact tension-shear specimen (Richard and Benitz 1983; Zipf and Bieniawski 1986), the edge cracked triangular specimen subjected to three point bending (Aliha et al. 2013; Mirsayar et al. 2018), the asymmetric edge notch disc bend specimen (Bahmani et al. 2020) and the cracked semi-circular bend specimen (Ayatollahi et al. 2006; Lim et al. 1994; Ameri et al. 2012; Aliha et al. 2012, 2016; Mirsayar et al. 2017; Torabi et al. 2018) are some of the specimens used frequently for mixed mode fracture tests on different engineering materials like metals, polymers, ceramics and rocks.

In the literature, several papers have been before worked regarding brittle fracture in $\mathrm{U}$ - and $\mathrm{V}$-notched domains under different loading conditions. Like for cracks, the same loading modes have been introduced also for notches, namely mode I, mode II, mode III, and mixed mode loadings. Most of the fracture assessments have been performed under mode I and mixed mode I/II loading conditions due to wide engineering applications. A number of fracture criteria are proposed by researchers and have been used for investigating mixed mode fracture in materials. They are the maximum tangential stress (MTS) criterion (Ayatollahi et al. 2006, Mirsayar and Samaei 2014), the maximum tangential strain (MTSN) criterion (Mirsayar et al. 2016), the tangential stress contour (TSC) criterion (Aliha et al. 2019), the maximum energy release rate criterion (Hussain et al. 1974), the minimum strain energy density criterion (Lazzarin and Zambardi, 2001; Sih 1974, Yosibash 2012) and critical notch stress intensity factor (NSIF) model used by Fodil et al. 2016; Gomez et al. 2009). Any of these fracture criteria can be used for predicting the direction of fracture initiation as well as the fracture load in cracked components and 
structures under mixed mode I/II loading stress-based (Ayatollahi and Torabi 2010; Chen and Ozaki, 2008; Torabi et al. 2014) and energy-based (Lazzarin et al. 2009; Priel et al. 2008; Sapora et al. 2013; Torabi and Berto 2014) criteria have been widely used for fracture assessments of notched members.

Among the many criteria currently applied, the recent criterion strain energy based (SED) returns its development to Sih (1973) which is based on the fact that brittle fracture is born when the mean value of the strain energy over a control volume which encircle a crack or notch tip reaches the critical energy for the un-notched material, Wc. The robustness of this criterion has been proved by several works on different notches geometries and on different loading conditions (Berto et al. 2015a,b; Berto and Lazzarin 2009,2014; Campagnolo et al. 2016; Gomez et al. 2007, Lazzarin et al. 2009, 2013). In this context (Aliha et al. 2017) has investigated the fracture of Perspex with four specimens subjected to three point bend loading based on the averaged strain energy density criterion in mixed mode I/II. The different notches were included in specimens ( $\mathrm{U}, \mathrm{V}, \mathrm{O}$ and keyhole notches), the mixed mode tensile/in-plane shear fracture toughness results from semi-circular and triangular crack type specimens are successfully predicted for sharp cracked PMMA samples using the SED criterion. Sih (1974) has analysed the propagation and fracture toughness for mixed problem based on the energy density. The result of this investigation indicates that the crack initiation occurs when the interior minimum of the strain energy density factor (i.e. $S$ value) reaches a critical value $\left(\mathrm{S}_{\mathrm{cr}}\right)$. Ayatollahi and aliha $(2007,2009)$ and Aliha and Ayatollahi, (2008) used a modified MTS criterion for predicting the mixed mode I/II fracture toughness data. In the modified MTS criterion, the effect of non-singular stress term (T-stress) was considered in addition to the stress intensity factors $\left(\mathrm{K}_{\mathrm{I}}\right.$ and $\mathrm{K}_{\mathrm{II}}$ ). Gomez et al. (2009) discussed the fracture of Vnotched specimens under mixed mode (I/II) to check the suitability of fracture criteria based on the cohesive zone model and strain energy density when applied to those samples. A modified MTS criterion was used by Ayatollahi and Aliha (2008) in mixed mode fracture tested by a centrally cracked Brazilian disc specimen for graphite materials. According to this criterion, the increase in the mixed mode fracture resistance of graphite can be attributed to the negative T-stress that exists in the BD specimen. In Khan and Khraisheh (2000), the maximum tangential stress criterion (MTS), was proposed and modified for ductile materials. A variable radius for the plastic core region based on Von Mises elastic plastic boundary is introduced and incorporated in the formulation of the MTS-criterion.

The aim of this paper is to study the effect of inclination of notch compared to load, under mixed mode I+II loading. An evaluation of notch stress intensity factor (NSIF) is examined for the variation of fields stress in vicinity of notch tip from BD specimen for different values of notch angle and radius. The local approach based on strain energy density approach is also used for analysing the behaviour of specimen under mixed mode and evaluating the main parameters of this method (i.e. the mean value of the strain energy (SED) and control volume).

\section{Material and Specimen}

The disc specimen is made of high strength steel (46SiCrMo6 grade). Its chemical composition is determined using a Thermo Fisher Scientific apparatus and is shown in Table 1.

Table 1. Chemical analysis of used material

\begin{tabular}{llllllllll}
\hline Element & $\mathrm{Si}$ & $\mathrm{Mo}$ & $\mathrm{Ni}$ & $\mathrm{P}$ & $\mathrm{Fe}$ & $\mathrm{S}$ & $\mathrm{Mn}$ & $\mathrm{Cr}$ & $\mathrm{Cu}$ \\
\hline $\mathrm{Wt} \%$ & 1.31 & 0.22 & 0.22 & 0.013 & 96.968 & 0.025 & 0.55 & 0.60 & 0.27 \\
Error & \pm 0.004 & \pm 0.002 & \pm 0.034 & \pm 0.062 & \pm 0.085 & \pm 0.085 & \pm 0.031 & \pm 0.012 & \pm 0.026 \\
\hline
\end{tabular}

In this study a computation by the finite element method was presented in the cast $3 \mathrm{~m}$ code, on a Brazilian disc specimen with a diameter $40 \mathrm{~mm}$ and a U-shaped notch was introduced with a depth of $4 \mathrm{~mm}$. Fig. 1 shows schematically the geometry and loading configuration of the proposed mixed mode I/II specimen. Two diametrically opposed compressions charges are applied to the specimen of intensity $3200 \mathrm{~N}$, and the notch is positioned relative to the load of different angle values which are $\left(\alpha=15^{\circ}, 30^{\circ}, 45^{\circ}, 60^{\circ}\right.$ and $\left.90^{\circ}\right)$ and a 
notch radius variation is used ( $\rho=0.25,0.3,0.5$ and $2 \mathrm{~mm}$ ). When $\alpha$ is $\pi / 2$ relative to the charge, the specimen is subjected to pure mode I, the specimen tends to compress under the action of compressions forces, deformations will be generated due to specimen configuration, but for the other angles the mixed mode will be dominant. The combined action of each mode I and II can lead to material damage when their weighted sum is equal to 1 (Aliha et al. 2017). The calculation is carried out in a plane deformation mode with a fine mesh applied in the vicinity of notch tip by means of six-node triangular element.
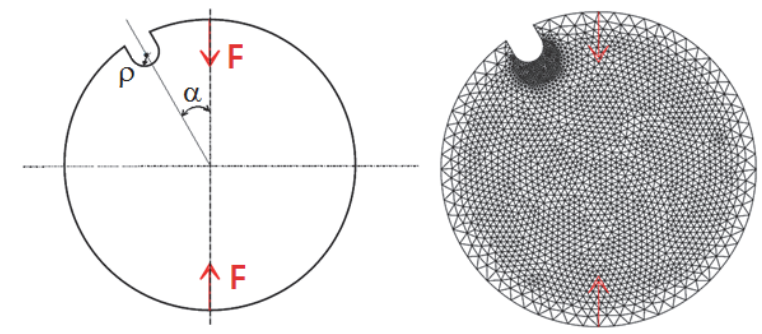

Fig. 1. Finite elements model

\section{Distribution of stresses in Brazilian disk specimen}

In the case where a notch in a BD specimen oriented at an angle has been introduced relative to the direction of the load, the stress field generated will be modified near the notch root. The expressions governing this field in a thin isotropic disc without a flaw are given by Mitchell (1961):

$$
\begin{aligned}
& \sigma_{x}=-\frac{2 P}{\pi B}\left[\frac{(R-y) x^{2}}{r_{1}^{4}}+\frac{(R+y) x^{2}}{r_{2}^{4}}-\frac{1}{D}\right] \\
& \sigma_{y}=-\frac{2 P}{\pi B}\left[\frac{(R-y)^{3}}{r_{1}^{4}}+\frac{(R+y)^{3}}{r_{2}^{4}}-\frac{1}{D}\right] \\
& \tau_{x y}=\frac{2 P}{\pi B}\left[\frac{(R-y)^{2} x}{r_{1}^{4}}-\frac{(R+y)^{2} x}{r_{2}^{4}}\right] \\
& r_{1}^{2}=(R-y)^{2}+x^{2} \\
& r_{2}^{2}=(R+y)^{2}+x^{2}
\end{aligned}
$$

$\mathrm{P}$ is the load applied, D is the diameter of the disk specimen and B is the thickness of the disc specimen. At the center of the disc:

$$
\begin{aligned}
& \sigma_{x}(0,0)=\frac{2 P}{\pi B D} \\
& \sigma_{y}(0,0)=-\frac{6 P}{\pi B D} \\
& \tau_{x y}(0,0)=0
\end{aligned}
$$

\section{Fracture parameters for mixed mode I/II emanating from notch}

Creager and Paris (1967) have extended the Irwin analysis to express the constraint field at a U-notch (shown in Fig. 2). They considered an elliptic hole in an infinite dimensional plate subjected to an overall stress in the direction of the minor axis of the ellipse, and determined the distribution of the constraints in the neighbourhood of the hole. They proposed the following hypothesis: the distribution of the stresses in bottom of notch is identical to that of a crack, but shifted in the direction of the bottom of notch a distance equal to $\rho / 2$. 


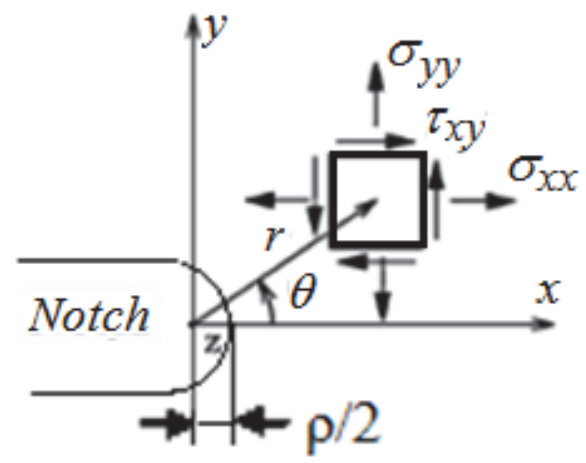

Fig. 2. Stress field at blunt notch background according to Creager and Paris

In these conditions, the elastic stress field near the root of a notch subjected to tensile loading can be written approximately for the $\theta=0$ directions as follows (Fig. 3):

$$
\begin{aligned}
& \sigma_{y y}=\frac{K}{\sqrt{2 \pi x}}\left(1+\frac{\rho}{2 x}\right) \\
& \sigma_{x x}=\frac{K}{\sqrt{2 \pi x}}\left(1-\frac{\rho}{2 x}\right)
\end{aligned}
$$

The stress intensity factor $\mathrm{K}_{\mathrm{I}}$ of cracks under tensile loading transverse to the crack (mode I) can be determined by considering the maximum notch stress $\sigma_{\max }$ of the relevant notch problem in which the notch radius is decreasing to zero:

$$
K_{I}=\lim _{\rho \rightarrow 0} \frac{1}{2} \sigma_{\max } \sqrt{\pi \rho}
$$

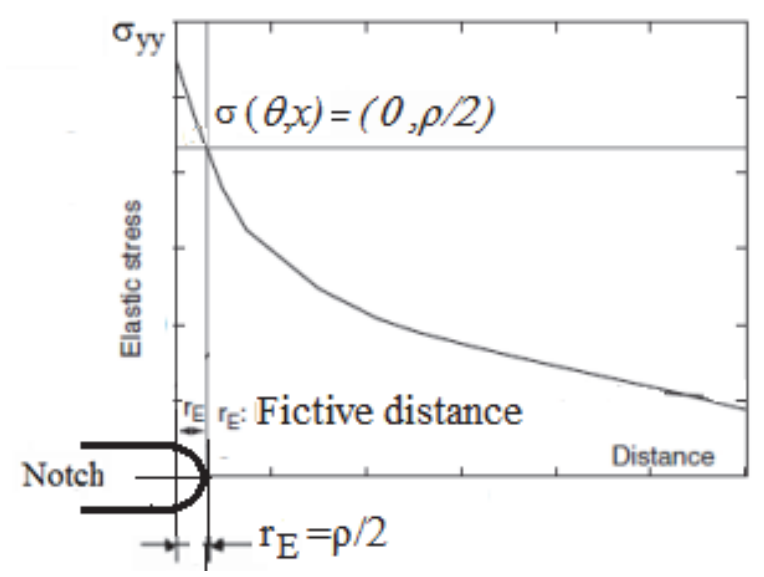

Fig. 3. Elastic stress distribution $\sigma_{y y}$ in the plane of notch

According to Radaj and Vormwald (2013), a relationship was suggested that has been derived for inplane shear loading (mode II) for parabolic shaped notch depending on the notch radius as:

$$
K_{I I} \approx 3.6742 \tau_{\max } \sqrt{\pi \rho}
$$

\section{Analytical background of the strain energy density approach}

The averaged strain energy density approach (ASED) can be used to characterize the level of stresses at the notch tip with lower computation efforts, because the average SED is less sensitive to mesh size (Berto et al. 2017; Lazzarin et al. 2008; 2010, Aliha et al. 2017). In other words, the precision of results is independent of the mesh fineness with a coarse mesh, the results obtained are comparable with the fine mesh (Luo et al. 2018). The basic idea behind the local strain energy density (SED) approach corresponds 
to Neuber's concept of an 'elementary material volume' or 'microstructural support length' used for stress averaging (Neuber and Kerbspannungslehre, 1958). The average SED in a defined control volume around the notch extremity (or crack) is considered to be the material parameter which describes the initiation of brittle fracture or high-cycle fatigue failure. The approach was originally named 'finite volume energy-based approach' or 'equivalent strain energy density approach' (Lazzarin and Zambardi, 2001), and later on 'local strain energy density approach' (Lazzarin et al. 2008). The concept of averaged strain energy based (SED) is based on the fact that brittle fracture is born when the mean value of the strain of energy over a control volume which encircles a notch tip is equal to the critical energy for the un-notched material, $W \mathrm{c}$. This critical value is a material characteristic parameter and does not depend on the notch geometry and sharpness. If the material behavior is ideally brittle, then $W \mathrm{c}$, can be evaluated by using simply the conventional ultimate tensile strength $\sigma_{t}$, so that $W_{c}=\sigma_{t}^{2} /(2 E)$. In plane problems, the control volume becomes a circle or a circular sector with a radius $R_{0}$ in the case of cracks or pointed $\mathrm{V}$-notches in mode I or mixed, I + II, mode loading. In the case of blunt notches, the area assumes a crescent shape, with $R_{0}$ being its maximum width as measured along the notch bisector line (Fig. $4 \mathrm{a}$ ) as stated by (Lazzarin and Berto, 2005). Under mixed-mode loading, the control area is no longer centered with respect to the notch bisector, but rigidly rotated with respect to it and centered on the point where the maximum principal stress reaches its maximum value (Fig.6) (Berto et al. 2007; Gomez et al. 2007). This rotation is shown in Fig. 4b where the control area is drawn for a U-shaped notch both under mode I loading (Fig. 4a) and mixed-mode loading (Fig. 4b).

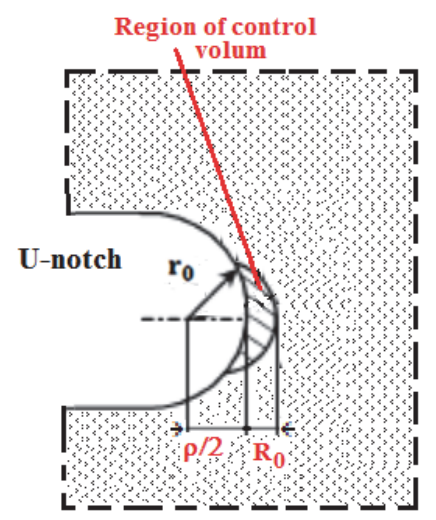

a)

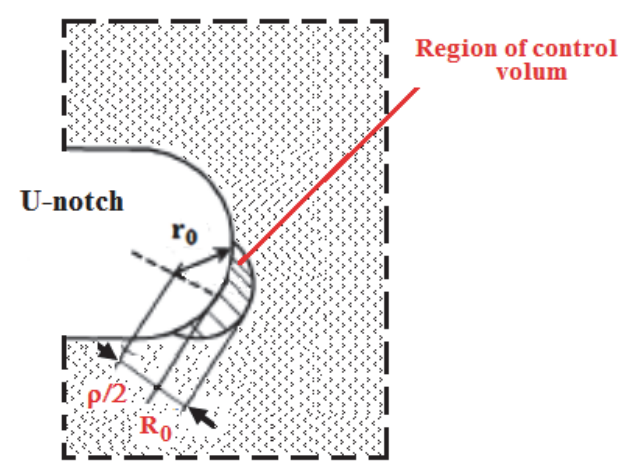

b)

Fig. 4. Critical volume for notched blunt U-shaped under:

(a) mode I and (b) mixed mode loading.

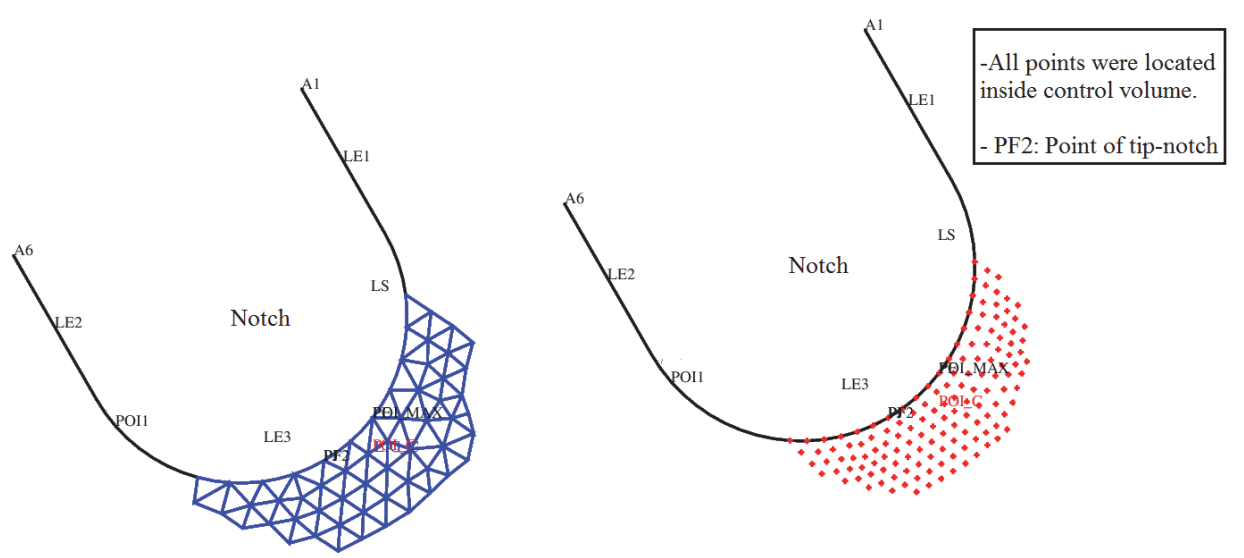

Fig. 5. Meshing elements in the volume control near the notch tip 
For a U-notch, the damage accumulation is localized at the notch end designated by the volume surrounding the arc of notch and is assumed to be the crescent shape where $\mathrm{R}_{0}$ is the distance measured along the bisecting line (Fig. 5). The obtained shaped area rounded near the notch background has a total radius equal to the sum of ' $\mathrm{R}_{0}+\mathrm{r}_{0}$ ' (see Fig. $4 \mathrm{a}$ and $4 \mathrm{~b}$ ). $\mathrm{r}_{0}$ is expressed according to the following expression in (Ayatollahi and Torabi 2010, Richard et al. 2005), which depends on the opening angle and radius of the notch. $r_{0}=\rho(\pi-2 \alpha)(2 \pi-\alpha)$.
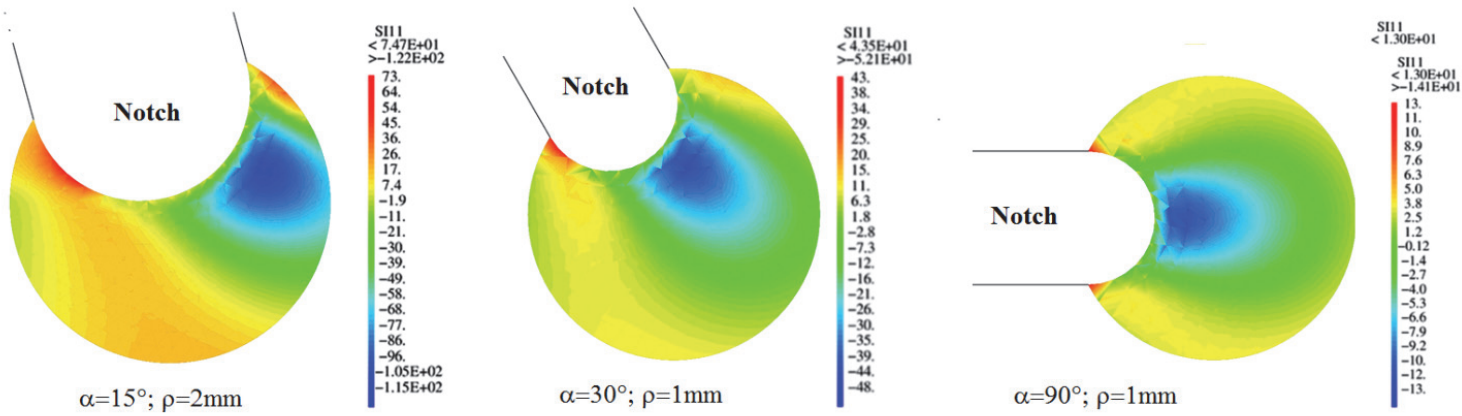

Fig. 6. Principal stress in MPa for different angle $\alpha$ and radius $\rho$ show the maximum of stress at the edge of notch, the crescent shape volume rotates rigidly under mixed mode

It is quite clear that during the calculation the crescent of the volume control zone has indeed rotated with respect to the bisecting line (Fig. 6) where the center of the zone is situated at the point which admits a maximum principal stress on the forehead of notch line. Under plane strain conditions, a useful expression for $R_{0}$ has been provided considering the crack case (Aliha et al. 2017; Berto et al. 2015), note that $R_{1 c}=R_{0}$ :

$$
R_{1 c}=\frac{(1+v)(5-8 v)}{4 \pi}\left(\frac{K_{I c}}{\sigma_{t}}\right)^{2}
$$

The relationship between the NSIFs and averaged SED (W) can be expressed as a function of the geometry and of the applied mode ratio; the values of $\mathrm{W}_{1}$ and $\mathrm{W}_{2}$ have (Aliha et al., 2017):

$$
\begin{aligned}
& W_{1}=\frac{e_{1}}{E}\left[\frac{K_{I}}{R_{1 c}^{0.5}}\right]^{2} \\
& W_{2}=\frac{e_{2}}{E}\left[\frac{K_{I I}}{R_{2 c}^{0.5}}\right]^{2}
\end{aligned}
$$

where $\mathrm{K}_{\mathrm{I}}$ and $\mathrm{K}_{\mathrm{II}}$ represent the mode I and mode II SIF ranges, $\mathrm{R}_{1}$ and $\mathrm{R}_{2}$, are the radii of the control volume related to mode I and mode III loadings, while $e_{i}(i=1,2)$ are parameters that depend on the opening angle and the Poisson's ratio. They are equal to 0.13449 and 0.341390 , respectively, according to Yosibash (2012). The total strain energy density when two modes acting together for the case of mixed mode I/II loading, it can be evaluated according to the following equation valid for both un-notched and notched components (Aliha et al., 2017; Berto et al., 2015):

$$
\mathrm{W}_{\mathrm{c}}=\mathrm{W}_{1}+\mathrm{W}_{2} \text {, }
$$

Eq. (16) can be rewritten as follows:

$$
W_{c}=\frac{\sigma_{t}^{2}}{2 E}+\frac{\tau_{t}^{2}}{2 G},
$$


where $\sigma_{t}$ is the ultimate tensile stress of flat specimen and $\tau_{t}$ is the ultimate shear strength of of the unnotched material and can be calculated approximately as:

$$
\tau_{t}=\sigma_{t} / \sqrt{2(1+v)}
$$

Under torsion loads, this critical value can be determined from the ultimate shear strength it according to Beltrami's expression Chang et al. (2002) for the un-cracked material:

$$
\mathrm{W}_{2 \mathrm{c}}=\frac{\tau_{\mathrm{t}}^{2}}{2 \mathrm{G}}
$$

Dealing here with sharp notches under mode II loading, the control radius $R_{2 c}$ can be estimated by means of the following equation first proposed by Berto et al. (2015):

$$
R_{2 c}=\frac{(9-8 v)}{8 \pi}\left(\frac{K_{I I c}}{\tau_{t}}\right)^{2}
$$

where $K_{I I_{C}}$ is the critical notch stress intensity factor for mode II.

According to Richard et al. (2005) it is possible to approximately estimate the mode II fracture toughness $\mathrm{K}_{\text {IIc }}$ as a function of $\mathrm{K}_{\mathrm{Ic}}$, it can expressed as:

$$
K_{I I C} \cong K_{I c}(\sqrt{3} / 2)
$$

According to used material, the ultimate tensile stress is equal to $\sigma_{t}=1662 \mathrm{MPa}$, by using the expression (18) the ultimate shear strength take the value $\tau_{t}=1038.75 \mathrm{MPa}$. The critical SED values of $\mathrm{W}_{1 \mathrm{c}}$ and $\mathrm{W}_{2 \mathrm{c}}$ take the same value that is equal to $6.575 \mathrm{MJ} / \mathrm{m}^{3}$. In parallel, the control volume definition via the control radius needs the knowledge the critical stress intensity factor $K_{I}$ and $K_{I I}$, the value of $K_{I C}$ that is correspond to the material is $97 \mathrm{MPa}$ and for mode II, $K_{I I C}$ takes the value $84 \mathrm{MPa}$.

\section{Results and discussions}

\subsection{Fields of stresses emanating of notch root in BD specimen}

The stress distribution is governed by Mitchell expressions for a flawless Brazilian disk specimen, the specimen is compressed under the effect of two opposite charges and the selected U-notch generates a nonuniform stress field. During the application of the loads, the notched specimen undergoes a deformation which will modify the stress field in the vicinity of the notch root, the calculation made by the FEM in the presence of the notch and it is confronted with the results obtained by the expressions of Mitchell, which are used in particular for the Brazilian disc specimens without defects in order to determine the threshold of which the maximum stresses of the specimen with notch can reach and to examine the apparent critical zones in the specimen, the curves obtained are presented in Fig. 7 with a radius and angle, defined as a function of distance between the notch root and the centre of specimen. We choose the curves for $\rho / a$ equal to 0.5 , in these figures, they have shown the stresses $\sigma_{\mathrm{xx}}$ and $\sigma_{\mathrm{yy}}$ near the notch bottom are very close to the values obtained by Mitchell expressions, and a divergence is observed when approaching the specimen centre, the growth of the angle $(\alpha)$ and notch radius attenuated the amplitudes of the stresses. Near the notch tip, the stresses $\sigma_{\mathrm{yy}}$ are superior to the stresses $\sigma_{\mathrm{xx}}$ (Fig. 7), and in the specimen centre, the maximum values are taken by those of stresses $\sigma_{\mathrm{xx}}$. For all cases the calculations of shear stress near the notch tip, their values have zero value; there is no shear effect near the notch tip. For a low angle $\left(\alpha=15^{\circ}\right)$ the stress $\sigma_{\mathrm{xx}}$ are greater than the stress $\sigma_{\mathrm{yy}}$ in the area near the specimen centre and the maximum stress is given by $\sigma_{\mathrm{xx}}$, as the angles tend towards the growth, the constraints re-establishes their growth and the amplitudes obtained by FEM converge to those obtained by Mitchell expressions. All these stresses are compressions stresses. In conclusion, the notch 
position with respect to the application of the charges and the variation of radius, considerably influence the magnitudes of the stresses and disrupted the stress field.
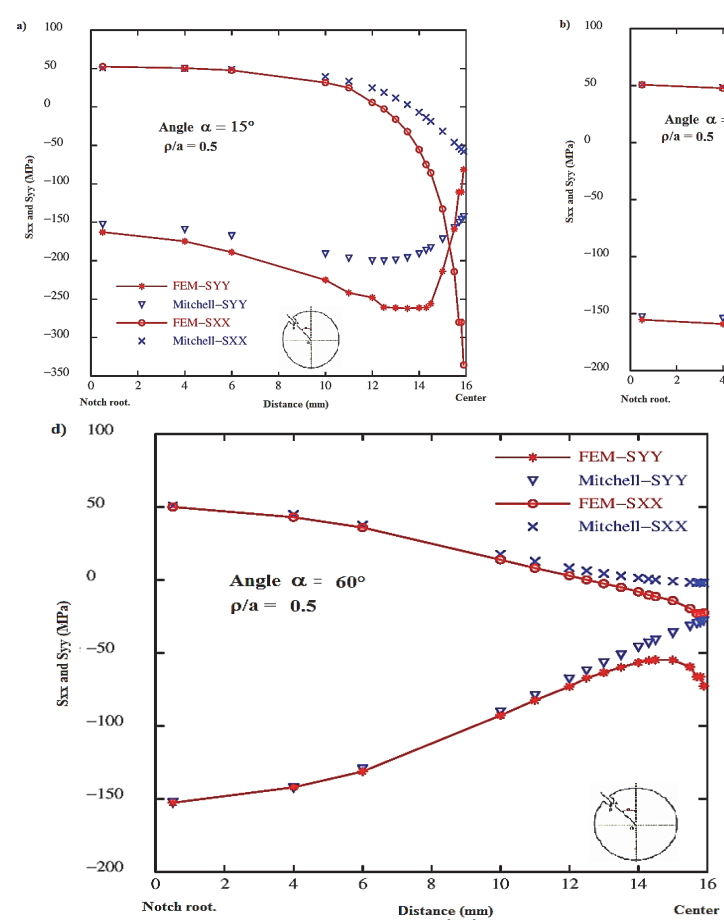
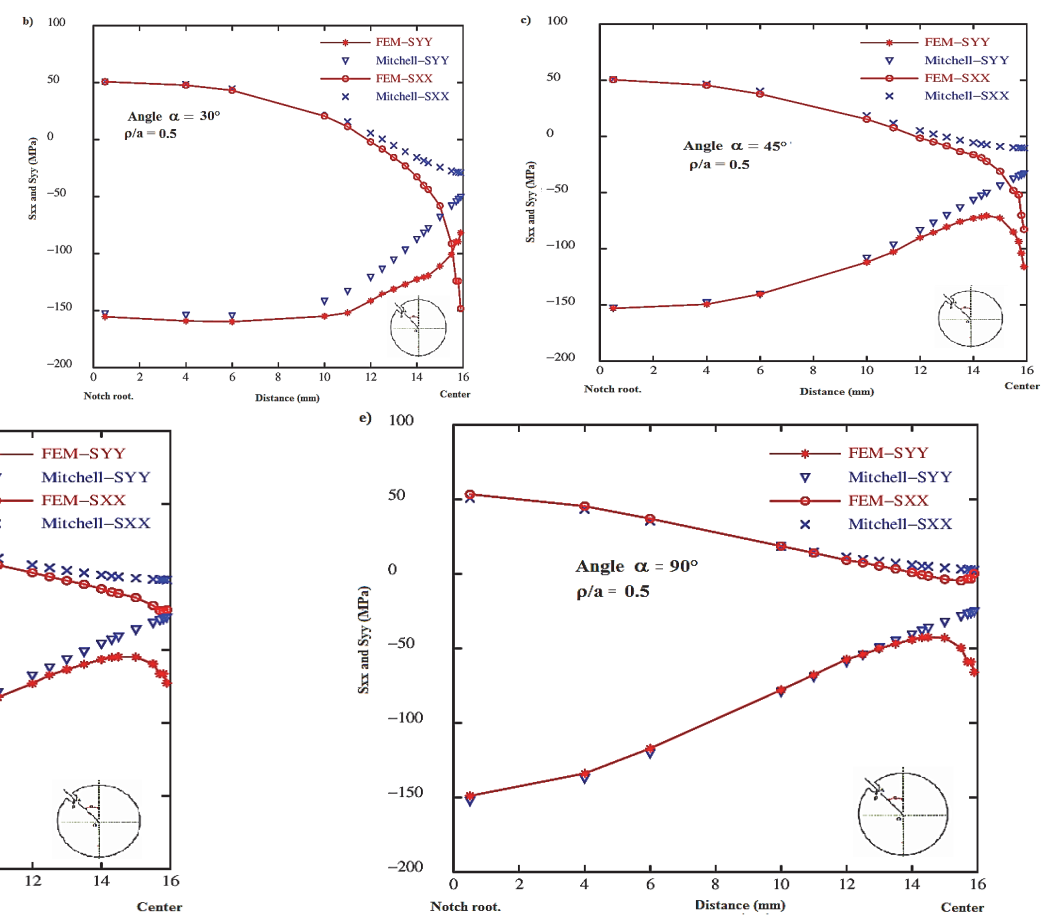

Fig. 7. Distribution of constraints $\sigma_{\mathrm{xx}}$ and $\sigma_{\mathrm{yy}}$ along radius distance $(\mathrm{OA})$

\subsection{Stress intensity factors evolution in mixed mode $K_{I}$ and $K_{I I}$}

\subsubsection{Influence of angle on factors $K_{I}$ and $K_{I I}$}

Fig. 8 show the evolution of mixed-mode SIF $\left(K_{I}\right.$ and $\left.K_{I I}\right)$ as a function of the angle. We used corresponding mathematical models to compare the difference between these models and FEM results and to determine the influence of notch radius variation and notch orientation angle on parameters $K_{I}$ and $K_{I I}$. The results obtained determine that the weak rays cause the increase of the SIF Ki (I,II) and the increase of the angles $\left(>80^{\circ}\right)$ mode I is dominant. Mode II is dominant when the angles are small or the rays are important. The increase of the angle leads to reduce the amplitudes of Ki, the convergence of results between FEM and mathematical relations occurs when the angles tend to increase.
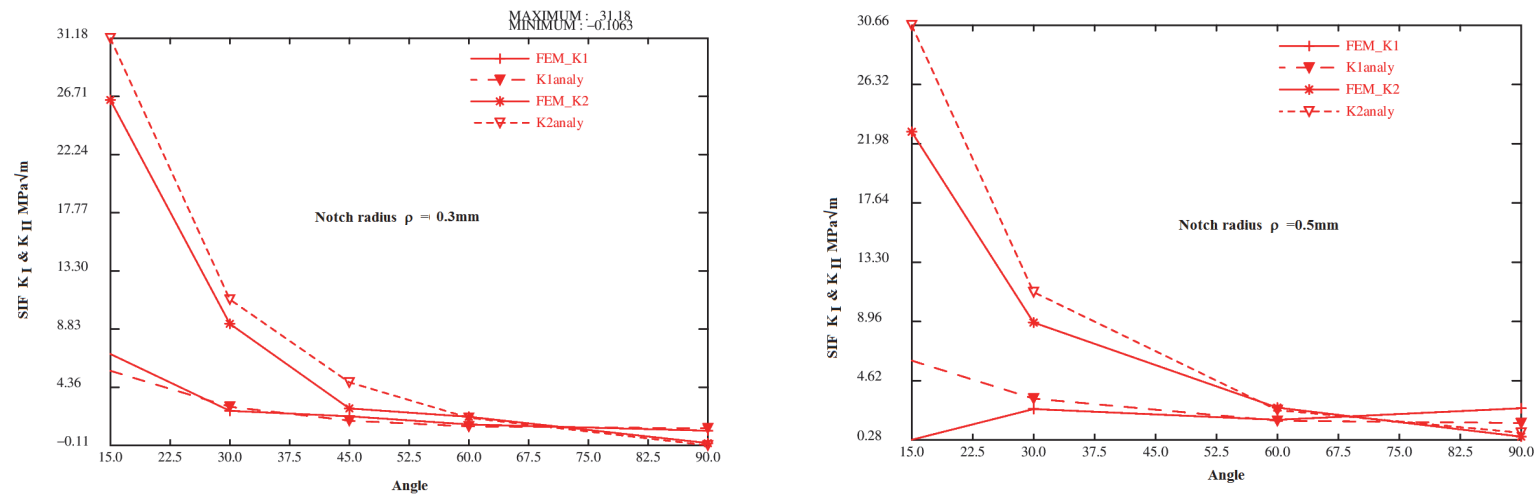

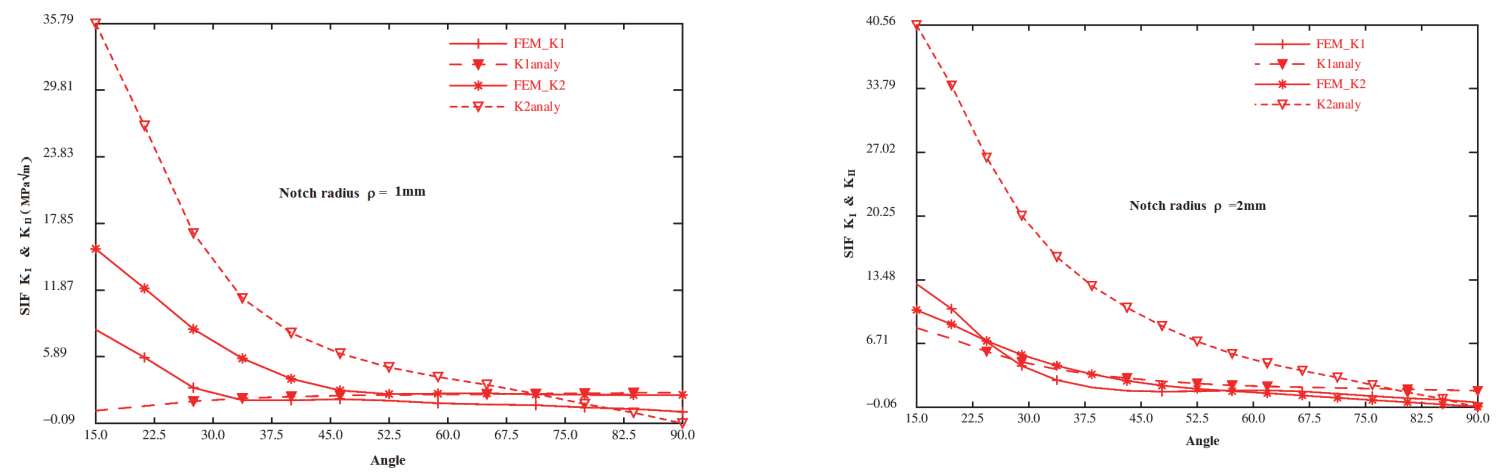

Fig. 8. Evolution of Stress intensity factors $\mathrm{K}_{\mathrm{I}}$ and $\mathrm{K}_{\mathrm{II}}$ vs. angle.

\subsubsection{Influence of notch radius on factors $K_{I}$ and $K_{I I}$}

Fig. 9 shows the influence of notch radius variation on stress intensity factors $K_{I}$ and $K_{I I}$, which translates, when increasing notch radius, both factors $K_{I}$ and $K_{I I}$ for each angles $\left(15^{\circ}, 30^{\circ}, 45^{\circ}, 60\right.$, and $90^{\circ}$ ) lead to decrease from the maximum towards the low values. The increase of notch radius leads to reduce of fracture parameters $\left(K_{I}\right.$ and $\left.K_{I I}\right)$.

a)

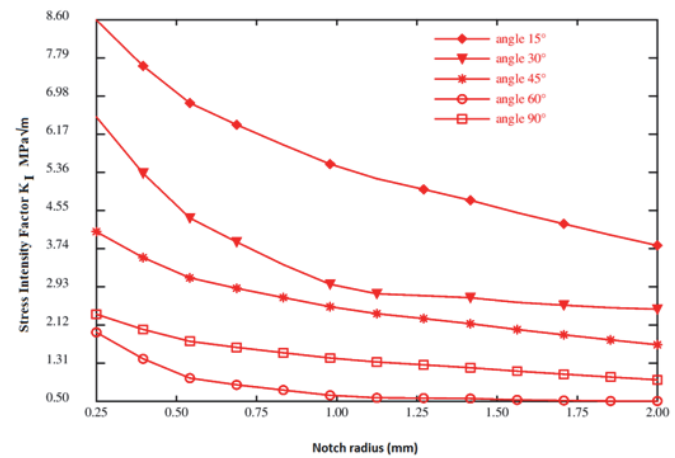

b)

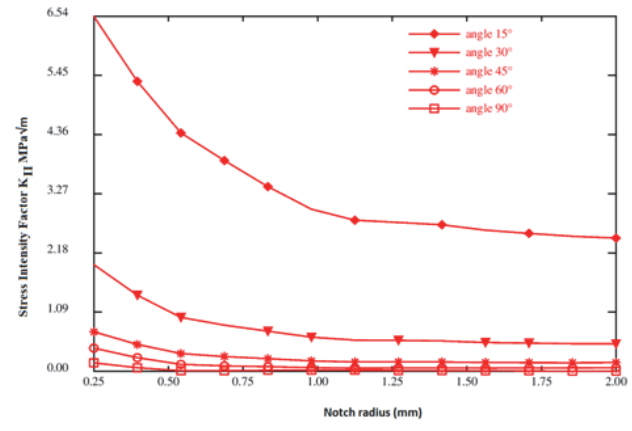

Fig. 9 Evolution of Stress intensity factors $\mathrm{K}_{\mathrm{I}}$ and $\mathrm{K}_{\mathrm{II}}$ vs. notch radius

\subsection{Strain energy density analysis}

In order to determine the mean value of the strain energy density (SED) relating to the different angle and radius of notch, the simulations were conducted under purely linear-elastic conditions, in a state of plane strain for the Brazilian disc specimen. According to the SED approach, the failure of a component is governed by a local parameter such as the total strain energy density; when its value, averaged over a circular control volume of critical radius Rc ahead of a crack or a notch tip, reaches the critical value Wc, the failure occurs (Lazzarin and Zambardi 2001). Berto and Lazzarin (2014), reported these critical parameters to be only material-dependent. This approach has been extensively used in the assessment of the tensile and fatigue behaviour of different materials weakened by several notch geometries (Berto et al. 2015; Berto and Lazzarin 2009). From this theory in (Lazzarin and Zambardi 2001), we applied it on the BD specimen subjected to two opposite charges in compression, the introduction of the notch in the specimen redistributes the stresses fields in a non-uniform way. Therefore the local energy will also be modified, if we are interested at the local level near the notch tip we used the approach SED to evaluate the incidence caused by the presence of the notch on the parameters of rupture namely volume control and the total energy over the controlled volume at a load level below critical loads. Hence, to limit the analysis only the effect of notch position and radius was studied. Fig. 10 shows the influence of different changes of radius and angle on these parameters. We can notice that these changes have a significant 
impact on the parameters of the SED-approach. The calculation allowed us to represent the total energy normalized with respect to the critical energy of the material as a function of the notch tip radius and angle, justifying the position of the notch relative to the load, the results obtained numerically are compared with those calculated by approximated expressions over the distance zone represented by $R_{1 c}$ and $R_{2 c}$ where the damage of the material can occur. Note that under a mixed mode, the center describing the sector $\mathrm{R}_{0}$ is located on the arc of notch tip where the main constraint is maximum. For small notch inclination angles i.e. $\left(\alpha<15^{\circ}\right.$, the notch is near the application of the load) the energy is higher than the amplitudes of energy when the angle is greater, on the other hand at higher angles the results converge between computations of analytical and numerical. The variation of notch radius also modifies the amount of elastic energy. Unlike the calculation of the SIF (stress intensity factors $\mathrm{K}_{\mathrm{i}}, \mathrm{i}=\mathrm{I}$,II), we can see that the increase of the notch radius will increase the local energy.
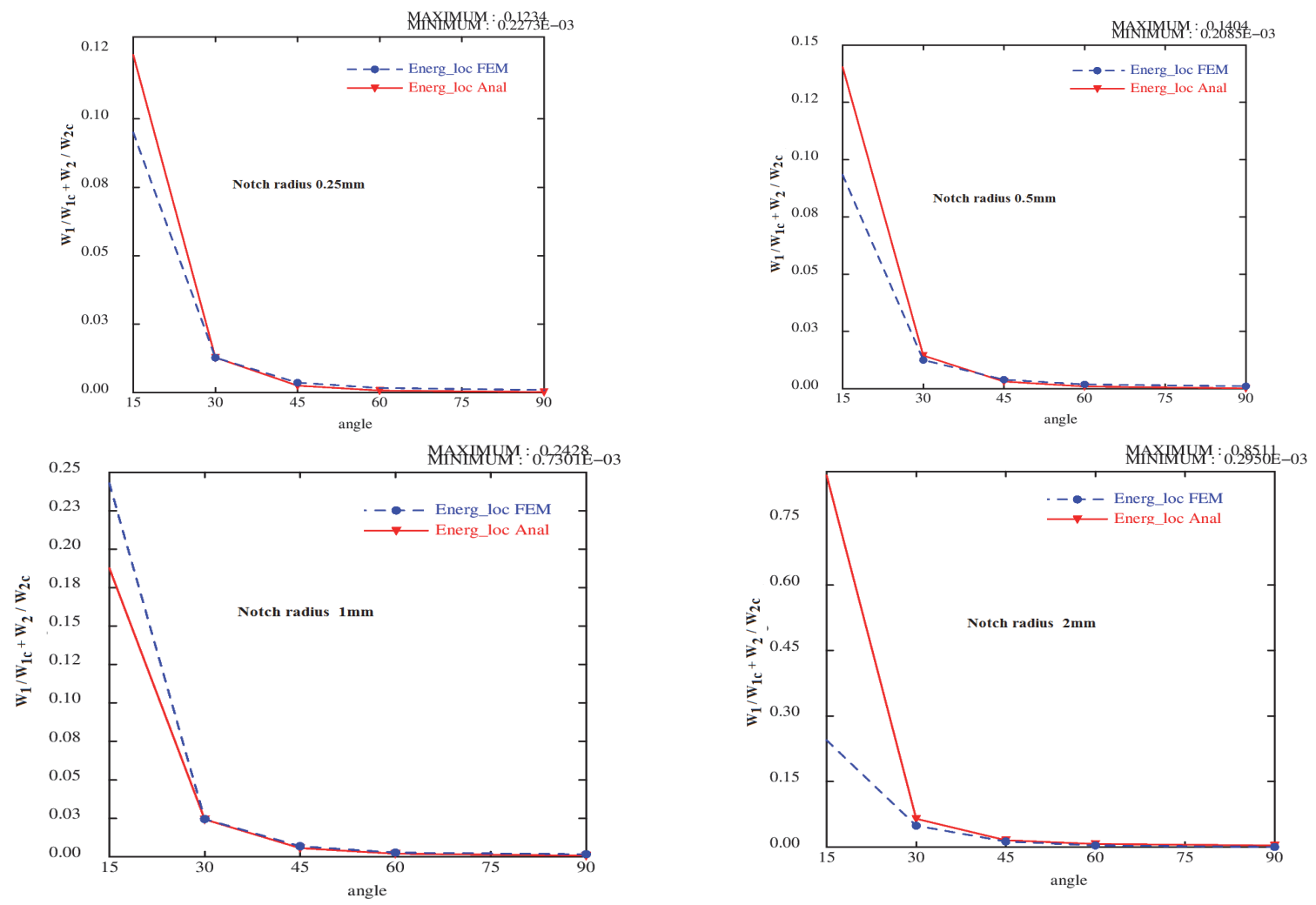

Fig. 10. Comparison between theoretical and numerical of Local strain energy density vs. angle

\section{Conclusions}

The present study is based on analysis of Brazilian disc specimen weakened by U-shaped notch under its position with respect to the application of load and also examined the disturbance to the stress field caused by the variation of notch radius. To this end we have applied the averaged strain energy density approach which is characterized by two main parameters mentioned in the literatures which are the averaged strain energy density over a control volume near the notch tip and the zone represented by sector of radius $\mathrm{R}_{0}$ which governs the control volume. At the examination level of the constraint field, we used expressions that govern the stress field which corresponds to this type of Brazilian disk specimen developed by Mitchell and compared with the computation obtained by the finite element method. After the results have been collected, we have noted that the results obtained using the finite elements calculation of the stresses in the vicinity of notch tip are approximately identical with the expressions of Mitchell. The stresses $\sigma_{\mathrm{xx}}$ and $\sigma_{\mathrm{yy}}$ near the notch tip are very close to the values obtained by Mitchell 
expressions, and a divergence is observed when approaching the specimen centre, the growth of the angle $(\alpha)$ and notch radius attenuated the amplitudes of the stresses. Near the notch tip, the stresses $\sigma_{y y}$ are greater to the stresses $\sigma_{\mathrm{xx}}$, and in the specimen centre, the maximum values are taken by those of stresses $\sigma_{\mathrm{xx}}$ for a small angle $\left(\alpha=15^{\circ}\right)$.

Notch position with respect to the application of the charges and the variation of radius, considerably influence the magnitudes of the stresses and disrupted the stress field. Near the notch tip the shear stress remains no effect on the behaviour of specimen compared to the level of stresses $\sigma_{\mathrm{xx}}$ and $\sigma_{\mathrm{yy}}$.

From the application of the SED- approach to the mixed mode, the average strain energy and the control volume represented by $R_{1 c}$ and $R_{2 c}$ make it possible to note the following points in terms of the fracture behaviour:

- Under mixed-mode loading, the control area is no longer centered with respect to the notch bisector, but rigidly rotated with respect to it and centered on the point where the maximum principal stress reaches its maximum value.

- For small notch inclination angles the mean value of the strain energy density (SED) in a circular sector of radius ' $\mathrm{R}$ ' located at the notch tip is important in the vicinity of the notch tip and can initiate the crack, if the external forces become great and the mean value of strain energy density exceeds the critical value; and when the angles tend to increase, the average strain energy density decreases from maximum values to minimum values.

- Also the variation of notch radius has an influence on the amplitude of the average strain energy density and the notch stress intensity factors. Its increase leads to attenuation of the amplitude of the notch stress intensity factors but it increases the local energy.

\section{Acknowledgements}

The authors would like to thank Pr. Mohamed SLAMANI, Mansour Rokbi and Nadir Douib, Mechanical Department, Faculty of Technolgie, University of Mohamed Boudiaf, M'sila (Algeria) for their encouragement and helpful suggestions. The authors would also like to thank Dr. Barhm Mohamad, Faculty of Mechanical Engineering and Informatics University of Miskolc - Hungary.

\section{References}

Akbardoost, J., Ayatollahi, M. R., Aliha, M. R. M., Pavier, M. J., \& Smith, D. J. (2014). Size-dependent fracture behavior of Guiting limestone under mixed mode loading. International Journal of Rock Mechanics and Mining Sciences, 71, 369-380.

Aliha, M. R. M., \& Ayatollahi, M. R. (2008). On mixed-mode I/II crack growth in dental resin materials. Scripta Materialia, 59(2), 258-261.

Aliha, M. R. M., Bahmani, A., \& Akhondi, S. (2016). Mixed mode fracture toughness testing of PMMA with different three-point bend type specimens. European Journal of Mechanics-A/Solids, 58, 148162.

Aliha, M. R. M., Berto, F., Mousavi, A., \& Razavi, S. M. J. (2017). On the applicability of ASED criterion for predicting mixed mode I+ II fracture toughness results of a rock material. Theoretical and Applied Fracture Mechanics, 92, 198-204.

Aliha, M. R. M., Heidari-Rarani, M., Shokrieh, M. M., \& Ayatollahi, M. R. (2012). Experimental determination of tensile strength and K (IC) of polymer concretes using semi-circular bend(SCB) specimens. Structural Engineering and Mechanics, 43(6), 823-833.

Ameri, M., Mansourian, A., Pirmohammad, S., Aliha, M. R. M., \& Ayatollahi, M. R. (2012). Mixed mode fracture resistance of asphalt concrete mixtures. Engineering Fracture Mechanics, 93, 153-167.

Aliha, M. R. M., Hosseinpour, G. R., \& Ayatollahi, M. R. (2013). Application of cracked triangular specimen subjected to three-point bending for investigating fracture behavior of rock materials. Rock mechanics and rock engineering, 46(5), 1023-1034. 
Aliha, M. R. M., Mousavi, S. S., \& Ghoreishi, S. M. N. (2019). Fracture load prediction under mixed mode I+ II using a stress based method for brittle materials tested with the asymmetric four-point bend specimen. Theoretical and Applied Fracture Mechanics, 103, 102249.

Aliha, M., Ashtari, R., \& Ayatollahi, M. R. (2006). Mode I and mode II fracture toughness testing for a coarse grain marble. Paper presented at the Applied mechanics and materials.

Aliha, M., Berto, F., Bahmani, A., \& Gallo, P. (2017). Mixed mode I/II fracture investigation of Perspex based on the averaged strain energy density criterion. Physical Mesomechanics, 20(2), 149-156.

Awaji, H., \& Sato, S. (1978). Combined mode fracture toughness measurement by the disk test. Journal of Engineering Materials and Technology, 100(2), 175-182.

Ayatollahi, M. R., \& Aliha, M. R. M. (2009). Mixed mode fracture in soda lime glass analyzed by using the generalized MTS criterion. International Journal of Solids and Structures, 46(2), 311-321.

Ayatollahi, M., \& Aliha, M. (2007). Fracture toughness study for a brittle rock subjected to mixed mode I/II loading. International Journal of Rock Mechanics and Mining Sciences, 44(4), 617-624.

Ayatollahi, M., \& Aliha, M. (2008). Mixed mode fracture analysis of polycrystalline graphite-a modified MTS criterion. Carbon, 46(10), 1302-1308.

Ayatollahi, M., \& Torabi, A. (2010). Investigation of mixed mode brittle fracture in rounded-tip Vnotched components. Engineering Fracture Mechanics, 77(16), 3087-3104.

Ayatollahi, M., Aliha, M., \& Hassani, M. (2006). Mixed mode brittle fracture in PMMA-an experimental study using SCB specimens. Materials Science and Engineering: A, 417(1-2), 348-356.

Bahmani, A., Aliha, M. R. M., Sarbijan, M. J., \& Mousavi, S. S. (2020). An extended edge-notched disc bend (ENDB) specimen for mixed-mode I+ II fracture assessments. International Journal of Solids and Structures, 193, 239-250.

Berto, F., \& Lazzarin, P. (2009). A review of the volume-based strain energy density approach applied to V-notches and welded structures. Theoretical and Applied Fracture Mechanics, 52(3), 183-194.

Berto, F., \& Lazzarin, P. (2014). Recent developments in brittle and quasi-brittle failure assessment of engineering materials by means of local approaches. Materials Science and Engineering: R: Reports, $75,1-48$.

Berto, F., Campagnolo, A., \& Ayatollahi, M. R. (2015). Brittle fracture of rounded V-notches in isostatic graphite under static multiaxial loading. Physical Mesomechanics, 18(4), 283-297.

Berto, F., Campagnolo, A., \& Gallo, P. (2015). Brittle failure of graphite weakened by V-notches: a review of some recent results under different loading modes. Strength of Materials, 47(3), 488-506.

Berto, F., Lazzarin, P., Gómez, F., \& Elices, M. (2007). Fracture assessment of U-notches under mixed mode loading: two procedures based on the 'equivalent local mode I'concept. International Journal of fracture, 4(148), 415-433.

Berto, F., Razavi, S., \& Ayatollahi, M. (2017). Some methods for rapid evaluation of the mixed mode NSIFs. Procedia Structural Integrity, 3, 126-134.

Campagnolo, A., Berto, F., \& Leguillon, D. (2016). Fracture assessment of sharp V-notched components under Mode II loading: a comparison among some recent criteria. Theoretical and Applied Fracture Mechanics, 85, 217-226.

Chang, S.-H., Lee, C.-I., \& Jeon, S. (2002). Measurement of rock fracture toughness under modes I and II and mixed-mode conditions by using disc-type specimens. Engineering geology, 66(1-2), 79-97.

Chen, D., \& Ozaki, S. (2008). Investigation of failure criteria for a sharp notch. International Journal of fracture, 152(2), 63-74.

Choi, S., Zhu, D., \& Miller, R. (2005). Fracture behavior under mixed-mode loading of ceramic plasmasprayed thermal barrier coatings at ambient and elevated temperatures. Engineering Fracture Mechanics, 72(13), 2144-2158.

Creager, M., \& Paris, P. C. (1967). Elastic field equations for blunt cracks with reference to stress corrosion cracking. International Journal of Fracture Mechanics, 3(4), 247-252.

Erdogan, F., \& Sih, G. (1963). On the crack extension in plates under plane loading and transverse shear. Journal of basic engineering, 85(4), 519-525. 
Fakhri, M., Amoosoltani, E., \& Aliha, M. R. M. (2017). Crack behavior analysis of roller compacted concrete mixtures containing reclaimed asphalt pavement and crumb rubber. Engineering Fracture Mechanics, 180, 43-59.

Fodil, L., El Azzizi, A., \& Hadj Meliani, M. (2016). Estimation of Mixed-Mode Stress Intensity Factors with Presence of the Confinement Parameters T-Stress and A3. Paper presented at the Advanced Engineering Forum.

Gómez, F., Elices, M., Berto, F., \& Lazzarin, P. (2007). Local strain energy to assess the static failure of U-notches in plates under mixed mode loading. International Journal of fracture, 145(1), 29-45.

Gómez, F., Elices, M., Berto, F., \& Lazzarin, P. (2009). Fracture of V-notched specimens under mixed mode (I+ II) loading in brittle materials. International Journal of fracture, 159(2), 121-135.

HUSSAIN, M. (1974). Strain energy release rate for a crack under combined mode I and mode II. Franture Analysis ASTM STP 560, 2-28.

Khan, S. M., \& Khraisheh, M. K. (2000). Analysis of mixed mode crack initiation angles under various loading conditions. Engineering Fracture Mechanics, 67(5), 397-419.

Kullmer, G., \& Richard, H. (2006). Influence of the root radius of crack-like notches on the fracture load of brittle components. Archive of Applied Mechanics, 76(11-12), 711-723. doi: https://doi.org/10.1007/s00419-006-0089-6

Lazzarin, P., \& Berto, F. (2005). Some expressions for the strain energy in a finite volume surrounding the root of blunt V-notches. International Journal of fracture, 135(1-4), 161-185.

Lazzarin, P., \& Zambardi, R. (2001). A finite-volume-energy based approach to predict the static and fatigue behavior of components with sharp V-shaped notches. International Journal of fracture, 112(3), 275-298.

Lazzarin, P., Berto, F., \& Ayatollahi, M. (2013). Brittle failure of inclined key-hole notches in isostatic graphite under in-plane mixed mode loading. Fatigue \& Fracture of Engineering Materials \& Structures, 36(9), 942-955.

Lazzarin, P., Berto, F., \& Zappalorto, M. (2010). Rapid calculations of notch stress intensity factors based on averaged strain energy density from coarse meshes: Theoretical bases and applications. International Journal of Fatigue, 32(10), 1559-1567.

Lazzarin, P., Berto, F., Elices, M., \& Gómez, J. (2009). Brittle failures from U-and V-notches in mode I and mixed, I+ II, mode: a synthesis based on the strain energy density averaged on finite-size volumes. Fatigue \& Fracture of Engineering Materials \& Structures, 32(8), 671-684.

Lazzarin, P., Berto, F., Gomez, F., \& Zappalorto, M. (2008). Some advantages derived from the use of the strain energy density over a control volume in fatigue strength assessments of welded joints. International Journal of Fatigue, 30(8), 1345-1357.

Lim, I., Johnston, I., Choi, S., \& Boland, J. (1994). Fracture testing of a soft rock with semi-circular specimens under three-point bending. Part 2-mixed-mode. Paper presented at the International journal of rock mechanics and mining sciences \& geomechanics abstracts.

Luo, P., Zhang, Q., Bao, Y., \& Zhou, A. (2018). Fatigue evaluation of rib-to-deck welded joint using averaged strain energy density method. Engineering Structures, 177, 682-694.

Mirsayar, M. M., Berto, F., Aliha, M. R. M., \& Park, P. (2016). Strain-based criteria for mixed-mode fracture of polycrystalline graphite. Engineering Fracture Mechanics, 156, 114-123.

Mirsayar, M. M., Razmi, A., Aliha, M. R. M., \& Berto, F. (2018). EMTSN criterion for evaluating mixed mode I/II crack propagation in rock materials. Engineering Fracture Mechanics, 190, 186-197.

Mirsayar, M., \& Samaei, A. (2014). Application of maximum tangential stress criterion in determination of fracture initiation angles of silicon/glass anodic bonds. Engineering Solid Mechanics, 2(3), 145150 .

Mirsayar, M., Shi, X., \& Zollinger, D. (2017). Evaluation of interfacial bond strength between Portland cement concrete and asphalt concrete layers using bi-material SCB test specimen. Engineering Solid Mechanics, 5(4), 293-306.

Mitchell, N. B., Jr. (1961). The Indirect Tension Test for Concrete. Materials Research and Standards, ASTM, 1(10), 780-787. 
Mousavi, A., Aliha, M. R. M., \& Imani, D. M. (2020b). Effects of biocompatible Nanofillers on mixedmode I and II fracture toughness of PMMA base dentures. Journal of the Mechanical Behavior of Biomedical Materials, 103, 103566.

Mousavi, S. S., Aliha, M. R. M., \& Imani, D. M. (2020a). On the use of edge cracked short bend beam specimen for PMMA fracture toughness testing under mixed-mode I/II. Polymer Testing, 81, 106199.

Neuber, H., \& Kerbspannungslehre, B. (1958). Gottingen Heidelberg: Springer.

Priel, E., Yosibash, Z., \& Leguillon, D. (2008). Failure initiation at a blunt V-notch tip under mixed mode loading. International Journal of fracture, 149(2), 143-173.

Radaj, D., \& Vormwald, M. (2013). Advanced methods of fatigue assessment: Springer.

Razavi, S. M. J., Aliha, M. R. M., \& Berto, F. (2018). Application of an average strain energy density criterion to obtain the mixed mode fracture load of granite rock tested with the cracked asymmetric four-point bend specimens. Theoretical and Applied Fracture Mechanics, 97, 419-425.

Richard, H. (1989). Specimens for investigating biaxial fracture and fatigue processes. Biaxial and multiaxial fatigue, EFG3, 217-229.

Richard, H. A., Fulland, M., \& Sander, M. (2005). Theoretical crack path prediction. Fatigue \& Fracture of Engineering Materials \& Structures, 28(1-2), 3-12.

Richard, H., \& Benitz, K. (1983). A loading device for the creation of mixed mode in fracture mechanics. International Journal of fracture, 22(2), R55-R58.

Sapora, A., Cornetti, P., \& Carpinteri, A. (2013). A Finite Fracture Mechanics approach to V-notched elements subjected to mixed-mode loading. Engineering Fracture Mechanics, 97, 216-226.

Seed, G., \& Nowell, D. (1994). Use of the distributed dislocations method to determine the T-stress. Fatigue \& Fracture of Engineering Materials \& Structures, 17(5), 605-618.

Shetty, D. K., Rosenfield, A. R., \& Duckworth, W. H. (1987). Mixed-mode fracture in biaxial stress state: application of the diametral-compression (Brazilian disk) test. Engineering Fracture Mechanics, 26(6), 825-840.

Sih, G. (1973). Some basic problems in fracture mechanics and new concepts. Engineering Fracture Mechanics, 5(2), 365-377.

Sih, G. C. (1974). Strain-energy-density factor applied to mixed mode crack problems. International Journal of fracture, 10(3), 305-321.

Suresh, S., Shih, C., Morrone, A., \& O'Dowd, N. (1990). Mixed-mode fracture toughness of ceramic materials. Journal of the American Ceramic Society, 73(5), 1257-1267.

Tamine, T., C. C., T. Boukharouba, and G. Pluvinage (Writer). (1996). Crack initiation in pure shear mode II, Problems of Strength, Special Publication.

Torabi, A. R., Kalantari, M. H., \& Aliha, M. R. M. (2018). Fracture analysis of dissimilar Al-Al friction stir welded joints under tensile/shear loading. Fatigue \& Fracture of Engineering Materials \& Structures, 41(9), 2040-2053.

Torabi, A., \& Berto, F. (2014). Mixed mode fracture assessment of U-notched graphite Brazilian disk specimens by means of the local energy. Structural Engineering and Mechanics, 50(6), 723-740.

Torabi, A., \& Pirhadi, E. (2015). Stress-based criteria for brittle fracture in key-hole notches under mixed mode loading. European Journal of Mechanics-A/Solids, 49, 1-12.

Torabi, A., Campagnolo, A., \& Berto, F. (2015). Local strain energy density to predict mode II brittle fracture in Brazilian disk specimens weakened by V-notches with end holes. Materials \& Design, 69, 22-29.

Torabi, A., Fakoor, M., \& Pirhadi, E. (2014). Fracture analysis of U-notched disc-type graphite specimens under mixed mode loading. International Journal of Solids and Structures, 51(6), 12871298.

Williams, J., \& Ewing, P. (1972). Fracture under complex stress - the angled crack problem. International Journal of Fracture Mechanics, 8(4), 441-446.

Xeidakis, G., Samaras, I., Zacharopoulos, D., \& Papakaliatakis, G. (1996). Crack growth in a mixedmode loading on marble beams under three point bending. International Journal of fracture, 79(2), 197-208. 
Yosibash, Z. (2012). Failure criteria for brittle elastic materials Singularities in Elliptic Boundary Value Problems and Elasticity and Their Connection with Failure Initiation (pp. 185-220): Springer.

Yukio, U., Kazuo, I., Tetsuya, Y., \& Mitsuru, A. (1983). Characteristics of brittle fracture under general combined modes including those under bi-axial tensile loads. Engineering Fracture Mechanics, 18(6), 1131-1158.

Zipf Jr, R. K., \& Bieniawski, Z. (1986). Mixed mode testing for fracture toughness of coal based on critical-energy-density. Paper presented at the The 27th US Symposium on Rock Mechanics (USRMS).

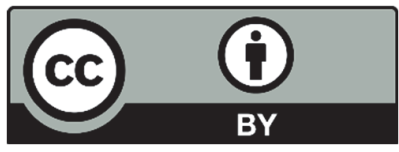

(C) 2020 by the authors; licensee Growing Science, Canada. This is an open access article distributed under the terms and conditions of the Creative Commons Attribution (CC-BY) license (http://creativecommons.org/licenses/by/4.0/). 